\title{
Using focus groups to understand breast cancer screening beliefs and behaviors among Asian I ndian women
}

\author{
Tsu-Yin Wu, Barbara Scheffer, Corinne Lee \\ School of Nursing, Eastern Michigan University, United States
}

Correspondence: Tsu-Yin Wu. Address: 328 Marshall Building, Ypsilanti, MI 48197. Telephone: 734-487-2297. Email: twu@emich.edu

Received: December 21, 2011

Accepted: March 5, 2012

Published: November 1, 2012

DOI : $10.5430 /$ jnep.v2n4p42

URL: http://dx.doi.org/10.5430/jnep.v2n4p42

\section{Abstract}

Background: Breast cancer is the most frequently diagnosed cancer and number one killer of Asian American women. Asian-Indian women living in the U.S. have a higher breast cancer incidence than Asian-Indian women in India and data in both the U.S. and the United Kingdom report that Southern Asian women have shown increasing rates of breast cancer over time. There is limited research on the root causes for under-utilization of breast cancer screening in Asian Indian (AI) women. The purpose of this study was to explore perceptions, knowledge, attitudes, beliefs, and practices of AI women living in the US in relation to breast cancer and breast cancer screening through the use of focus groups.

Method: A qualitative exploratory approach was achieved with focus groups. The focus group meetings were audio-taped, transcribed, and analyzed using constant comparison techniques. During the focus groups, the researchers collected data from 11 AI women between the ages of 42 and 71 years, who lived in the Midwestern U.S. and who shared their experiences with breast cancer screening.

Results: When asked about their perceptions about breast cancer, the emotion of fear was the most prominent within the two focus groups of Asian Indian women. Women participants shared that the role of care providers, family and friends, as well as other personal factors positively influenced their perceptions about breast cancer screening and their actual practices of the screening behavior. Barriers to breast cancer screening were identified as negative experiences, lack of access to screening, and inadequate knowledge about breast cancer screening.

Conclusions: Results of the focus group analysis provide useful information about facilitators and barriers that affect AI women's breast cancer screening practices in the US.

\section{Key words}

South Asian women, Mammography, Barriers

\section{Introduction}

Asian Americans represent one of the most rapidly growing populations in the United States (U.S.). According to the U.S. Census Bureau 2010 (2011), the population of Asian Americans was 17.3 million which accounts for $5.6 \%$ of the whole US population. Asian Indians are the third largest among Asian Americans (16\% of the Asian-American population) ${ }^{[1]}$. 
The Center for Disease Control and Prevention (CDC; 2010) defined Asian-Indians as the people residing in the U.S. who descend from any of the original peoples of India ${ }^{[2]}$. Among Asian Indian (AI) women, breast cancer is the most commonly diagnosed cancer and also the leading cause of cancer-related deaths for AI women ${ }^{[3]}$. According to the American Cancer Society (2001), AI women also have the second highest incidence of cancer among Asian American Pacific Islanders in the U.S. ${ }^{[4]}$.

Asian Indian women living in the U.S. have a higher breast cancer incidence than AI women in India ${ }^{[5,6]}$. In addition, data from both the U.S. and the United Kingdom indicate that Southern Asian women (whose ethnic origins are India, Pakistan, Bangladesh, Tamil, Sri Lanka or Bengal) have shown increased rates of breast cancer over time, while the rates have decreased among the rest of the populations from those countries ${ }^{[7,8]}$.

High-quality screening procedures are effective in substantially reducing cancer incidence and preventing many cancer-related deaths ${ }^{[9]}$. Several national medical professional groups such as the American Medical Association (AMA), the American Cancer Society (ACS), the American College of Obstetricians and Gynecologists (ACOG), and the U.S. Preventive Services Task Force (USPSTF) recommend mammography for women aged 40-plus annually or biennially and clinical breast exams (CBE) no less than once every two years for women 40 and over ${ }^{[10-12]}$. Higher incidence and death rates among some racial/ethnic groups indicate that certain populations/subgroups have not benefited equally from cancer prevention and control efforts ${ }^{[13]}$.

\section{Review of literature}

\subsection{Screening of Asian American women}

Despite the emphasis on the importance of early detection in breast cancer, breast cancer screening practices have shown the lowest rate among Asian American women. According to the data reported by CDC (2009), 55\% of Asian Pacific American women compared to $70 \%$ of white and black American women reported receiving a mammography in the past two years ${ }^{[14]}$. Specifically for AI women, a study in California reported 39\% of Southern Asians participated in mammography screening. Locally in Michigan, one study involving AI women noted that a small number of AI women had been screened with mammography in the past 13 months (58\%) and an even smaller percentage of that population received regular screening in the past five years (29\%) ${ }^{[15]}$. Another study with 160 AI women reported a slightly higher rate (63\%) because of the use of a longer interval for mammography screening (i.e., within the past two years) ${ }^{[16]}$. These rates are considerably lower than those seen in the general population and do not meet the Healthy People 2010 objective of a mammography screening rate of $70 \%$ among women aged 40 plus in the past two years ${ }^{[17,18]}$.

\subsection{Factors associated with screening}

Previous survey-based studies reported on the use of and factors associated with breast cancer screenings among AI American women ${ }^{[15,16,19,20]}$. Parkington et al. (2009) examined barriers to breast cancer screening in a managed care population of Asians ( $n=54)$, and the results showed three barriers for breast cancer screening: (a) mammography was not a priority, (b) bad experiences with breast cancer screening, and (c) knowledge deficits. Among these barriers, knowledge deficits was reported most often (74\%), with mammogram not being a priority (47\%) as the second most common response $^{[19]}$.

Cultural beliefs and values ingrained in AIs are likely to play an important role in influencing cancer screening use. Bottorff, Grewal, and Sullivan (2006) reported that the family is the center of a woman's life among AI women. These women believe that they protect their families if they ignore their illness since they believe that illness is fate or "kismet." Additionally, when one feels healthy, the practice of screening becomes not so important ${ }^{[21]}$. Wu, Hsieh, and West (2009) reported in a survey study $(\mathrm{n}=315)$ on the adoption of mammography among Asian Americans that the two barriers toward mammography screening were "Feeling OK" (46\%) and "Doctor did not recommend" (64\%) ${ }^{[15]}$.

Published by Sciedu Press 
Wu and Bancroft (2006) reported in a qualitative study on perceptions and experiences of Filipino-American women that those Filipino women avoided the word "cancer" because of fear and shock. The study also identified barriers such as unpleasant experiences with mammography ${ }^{[20]}$. Similarly, a qualitative study with Korean women who acknowledged bad previous experiences with mammography found that Korean women tended not to discuss bodily experiences and hesitated to show their breast to others ${ }^{[22]}$. While these studies provided cultural perspectives of Asian American women toward cancer and breast health, data are still needed to better understand the views of AI women.

There is limited research on the root causes for under-utilization of breast cancer screening in AI women. The purpose of this study was to explore perceptions, knowledge, attitudes, beliefs, and practices of AIs in relation to breast cancer and breast cancer screening through the use of focus groups. A qualitative approach with use of focus groups is well suited to this purpose. The findings of the study can provide a greater depth of understanding and potentially add to the current literature guiding potential strategies for developing culturally effective interventions that are sensitive to AI health beliefs for promoting breast cancer screening.

\section{Method}

\subsection{Research design}

This qualitative study used a focus group approach to explore the shared meaning of breast cancer and experiences with breast cancer screening among 11 AI American women. This method was chosen for data collection because group interactions provide a social context for the development of each participant's ideas so participant's thoughts and ideas can be stimulated ${ }^{[23-25]}$. In addition, the researchers were able to obtain data with greater depth than with individual interviews ${ }^{[26]}$. These Groups were kept small with 4-7 participants each to allow each woman time to share her thoughts i. Each session was held in a non-threatening environment and lasted about 90 minutes. During the focus group, the participants were able to exchange their views without being judged. This process effectively gathered information about Asian-Indian women' views on breast cancer, and current and past practices with breast cancer screening. Table 1 below highlights the participants' demographics.

\subsection{Participants}

Table 1. Demographic Characteristics of Participants

\begin{tabular}{|c|c|c|}
\hline Characteristic & $\mathbf{N}$ & $\%$ \\
\hline \multicolumn{3}{|l|}{ Age } \\
\hline $41-50$ & 3 & 30 \\
\hline $51-60$ & 4 & 40 \\
\hline $61-70$ & 2 & 20 \\
\hline$>70$ & 1 & 10 \\
\hline \multicolumn{3}{|l|}{ Marital status } \\
\hline Married & 9 & 90 \\
\hline Single/Widowed & 1 & 10 \\
\hline \multicolumn{3}{|l|}{ Occupation } \\
\hline Health-related profession & 1 & 10 \\
\hline Industry (seamstress) & 1 & 10 \\
\hline Housewife & 3 & 20 \\
\hline Education & 3 & 30 \\
\hline Technician & 3 & 30 \\
\hline \multicolumn{3}{|l|}{ Years residing in the United States } \\
\hline$<10$ & 1 & 10 \\
\hline $10-20$ & 2 & 20 \\
\hline$>20$ & 7 & 70 \\
\hline
\end{tabular}

Note. There were some missing data in the demographic variables. 
The mean age of women participants was 56 years ( $\mathrm{SD}=9.1$ years, range $=42$ to 71 years). One woman was excluded from the mean because her age was not obtained. More than half of the women (54.5\%) in the study sample were married (with four women not indicated whether they were married or not). The average length of residence in the U.S. was 23.6 years ( $S D=15.5$ years) with 1.5 years being the shortest and 46 years being the longest. The sample included women with a wide range of occupational background from homemaking, industry, technology, health care, and teaching/education for a total of 11 participants (see Table 1).

\subsection{Procedures}

In this study, a convenience sample of participants was recruited from the metropolitan area of southeastern Michigan through cultural/community centers, a temple, an Asian Indian website, and newsletters. Eligibility criteria were women who self-identify themselves as Asian Indian American, speak English, Punjabi or Hindi, and be aged 40 or older. Two separate focus groups were held at the locations which are convenient to and comfortable for the participants. The study was approved by the Institutional Human Subjects Review Committee, and all participants received and signed a copy of an informed consent before the start of data collection. The participants were assured that their identities would be kept confidential and all information would be reported as group data.

Each focus group session was led by a primary investigator and a bilingual research associate with the focus group guide developed in advance by the primary investigator. This guide was reviewed and validated by two cultural experts and one consultant for the study. The final interview guide was composed of seven questions (see Table 2) that were selected based on feedback received from the experts who have worked with this population.

Table 2. Questions Used in the Focus Groups

1. Would you please tell us about your experience (e.g., yourself, family members, friends) with breast cancer?

2 What does breast cancer screening mean to you?

3. What are your breast cancer screening practices in your own country?

4. What are your breast cancer screening practices when you come to the United States?

5. For women like you, what makes/motivates you to do breast self-examination/clinical examination/mammography?

6. For women like yourself, what makes it difficult for you to do breast self-examination/clinical examination/mammography?

7. In your view, what are some suggestions that would make it easier for you to do regular breast self-examination/clinical examination/mammography?

The assistant and primary investigator took notes, and the session was also audio-recorded with permission obtained at the beginning the session. During the session, the participants were encouraged to ask questions, and additional questions were posed by the researchers to clarify any unaddressed areas. Each participant received a $\$ 25$ gift certificates to a local grocery store as incentive and refreshments were served.

\subsection{Data analysis}

The focus groups meetings were audio-recorded and transcribed verbatim by a trained graduate research associate. Transcripts were verified by another researcher to ensure the accuracy. Both transcripts of the audiotapes and field notes served as the primary data used for analysis. The primary investigator and trained graduate research assistant independently reviewed the transcripts for content analysis and coded each line of the transcripts. Regular meetings between the researchers were conducted to address emerging patterns and compare the coding results. In addition, detailed discussions among these researchers were held to clarify differences; resolutions for inconsistencies were achieved by consensus. Data were analyzed by assigning preliminary labels to organizing themes in the text as recommended by Morgan and Kreuger ${ }^{[26]}$. Themes that were salient and repeated in the data were identified and kept in the preliminary data analysis. In order to determine consistency and establish credible research findings, preliminary conclusions of the first focus group were discussed with the participants at the second focus group at the end of the focus group meeting and a 
group of key community informants who were familiar with the issues of AI women. Participants were informed about the confidentiality of data and only aggregate results would be reported.

\section{Results}

\subsection{Reinforcing factors for breast cancer screening}

Women participants shared that the role of care providers, family and friends, as well as personal factors positively influenced their perceptions about breast cancer screening and their actual practices of the screening behavior.

Role of care providers. Doctor recommendations and referrals for mammograms were identified as key facilitating factors for mammograms. Participants $(n=8)$ reported that when their doctors recommended mammograms they mostly complied. Similarly, when their doctors reminded them that they were due for mammograms, they felt more committed to get it done. Participants also mentioned several strategies from the doctor's office helped, including sending women reminders when their mammograms are due and clarifying the frequency for the mammograms (yearly vs. once every two years). One woman described the inconsistency of her doctor's recommendation of mammogram intervals,

“My doctor said that I shouldn't get it done every year. I should get it done after two years so I just um...sleep on it.... She also said, because you are not high risk, because I have got it done so many times, you know in last 10-12 years, and she said now you should get it done after every two years.”

Another theme emerged under the category of the role of other healthcare providers who encouraged AI women to go for mammograms. Several women spoke about their positive experiences with other support staff where exams were taken. One woman stated that a comfortable atmosphere helped to relax her when she was waiting for her mammogram. In addition, several women spoke of the care of the technicians working with them. Two women spoke of gentle experiences that they had as motivating factors to come back for their next mammograms. A quote showed the explanation from the technician provided comfort for this woman:

"I had one...I said a good technician; she explained how they were going to do it and it was as good as video. She said they would do one breast first and then the second one. It will hurt a little but you will be okay. She explained to me everything before she started it."

Influences from family members and friends. Family is a major motivator for these women to get screened for breast cancer. Women participants expressed the need to be there for their families and wanting to avoid having their family care for them. As a result, personal health is important to them. Their comments included:

"I don't want to be dependent on anybody."

“...so I can take care of my family too, so they don't have to take care of me.”

One woman summed it up by saying,

“...don’t want to be a burden.”

Experience in these women's lives in regards to their friends who were diagnosed with breast cancer was a significant motivator for several of the women. Two participants said that as soon as they found out a friend was diagnosed with breast cancer, they began to participate in breast cancer screening on a regular basis. The following three quotes supported this theme regarding the impact of the friends: 
“...so some of my friends went through um...you know problems here, some came through late and it was painful to see that. They suffer for a short time (rest of sentence was muffled). Some of them, it was good they risk the chemotherapy, and I was thinking that I should start having check-up regularly".

"I would get it done more often," (in response to how her perceptions changed when her friend was diagnosed with cancer).

"You see other people you know around your age or your age group suffering, that can definitely make you aware, that it's better to get it done."

Personal factors. Participants reported several personal factors which motivated them to go for a mammogram. When the participants found a nodule or changes in their breasts, they felt motivated to obtain mammograms. The participants' personal goals were another important factor that facilitated them to go for a mammogram. One participant reported her sense of relief when her mammogram result was negative:

"It's a relief that you are free, and have peace of mind to find out that everything is okay." Another woman said, "Just to get relief that you are free."

\subsection{I nhibiting factors for obtaining breast cancer screening}

The barriers for the AI American women in this study to perform mammograms were categorized as negative experiences, lack of access to screening, and inadequate knowledge. Data from both focus groups were used to support these themes.

Negative experiences. The most common barrier to mammograms both in the United States and in India was the mammogram procedure itself. Participants reported pain as a factor that affected their willingness to go for mammograms. Focus group participants associated mostly negative feelings with mammography. Nine of the 11 women expressed their experiences with the mammograms were related to the pain, the cool temperature of the "slabs," and the rough treatment by the technicians. For instance:

"The pain you know...they squish it between the two slabs over there...."

"I don't think anybody is telling you the truth but I think that the pain, the pressing your breast that people try to avoid it."

One participant reported that for some Indian women going for mammograms may be a taboo, a sensitive topic to talk about: "I mean this is a taboo there...that nobody talked about especially this thing... it’s very fragile."

Lack of access to breast cancer screening. The participants $(n=8)$ reported that in India, most women do not have health insurance. The high out-of pocket cost limits Indian women for obtaining mammograms here in the U.S.; women who have health insurance through their employers or their husbands' employers are the only ones who have possibilities of getting their mammograms done.

Inadequate knowledge about breast cancer screening. Lack of awareness with regards to breast cancer screening is evident when the women were asked about breast cancer screening practices in their native country of India. Several women stated that this type of health education was not a part of the Indian government's mission when they lived in India 30 years ago. Several said that in the last 10 years or so, this has become part of the health education but in some geographic areas, women still do not practice this type of screening.

When referring to the terminology of clinical breast exams (CBE), the lack of knowledge was evident in the two focus groups when most participants verbalized that they did not know what some of the terminology meant. Most were able to 
describe that their doctors or nurses touched their breasts but were unaware that this was part of the routine in the modality for breast cancer screening.

In addition, several women $(\mathrm{n}=7)$ questioned the potential for unnecessary exposure to radiation in the mammogram. For example, one woman said:

“We do, do that...every two years but there’s a question, are we exposing ourselves too much to radiation?”

A second woman added:

"What about how good is this radiation..., cause there's so much..."

Another aspect of the "Inadequate knowledge about breast cancer screening" theme focused on participants who were not familiar with the purpose of regular cancer screening. One participant did not feel the need for screening when she perceives herself healthy. As a result, when in the women's views and perceptions they had no family history of breast cancer and/or their having apparently normal breasts, they were deterred from sustaining the habit of performing breast cancer screening.

"Some people are over confident that they are healthy and nobody in their family has had it."

“... if there's something, I mean you can see the difference in between the nipples and all that, since you know generally look seems okay”.

\subsection{Emotions connected with breast cancer and cancer screening}

When asked about their perceptions about breast cancer, the emotion of fear was the most prominent expression regarding breast cancer within both focus groups of AI American women. Several quotations best described these women's upper most emotional response as,

"The very word cancer, I think that scares you. Some people say that I don't even care if it's at an early stage it can be cured, but the very thought of cancer you know makes you scared and you think no and you are gone now."

“One other thing, I don't want to see that cancer floor, you know, name and everything you know."

Another fear was linked to metastases, according to one woman, "You might think that it's just breast cancer but it could have gone to other places.” Two participants avoided or delayed yearly mammogram because they were scared of the outcome; that is, being diagnosed with breast cancer. One woman said:

"You know, I can tell you, I'm still scared you know, to go to mammogram. I just don't feel like to go but I just push myself."

\section{Discussion}

This is one of the few studies that used qualitative methods to explore AI women's views on breast cancer and factors related to breast cancer screening. Major themes discovered in the final data analysis were supported with direct quotations from the transcripts. A final analysis of the identified themes revealed specific reinforcing factors of and barriers to breast cancer screening and provided insights about the perceptions, beliefs, attitudes, and practices of 11 AI women regarding breast cancer and breast cancer screening. Healthcare providers play an important role in breast cancer screening for AI 
women; when working with AI women, the motivating and inhibiting factors identified in this study should be considered when interacting with AI women about performing regular breast cancer screening.

The internal fears and concerns about cancer expressed by these women participants can be addressed in a nonthreatening way to motivate them to adhere to recommended screening guidelines. Ignoring or discounting their feelings may lead to avoidance and further discourage AI women from practicing screening modalities. Similar to a previous study in immigrant Filipino women in the U.S. ${ }^{[20]}$, pain and discomfort associated with the mammography was identified as a significant barrier in current study. Community-based outreach education may increase knowledge and reduce such negative feelings that this population of women experience during past examination. Women participants in this study also reported skepticism regarding whether or not they should get yearly mammograms based on what they had been told by their physicians and some worried about the effects of radiation, while others did not feel the need to go for mammograms if they were healthy and had no family history of breast cancer. Educational strategies (for example, continuing professional development) for primary care providers that emphasize cultural norms and beliefs may equip primary healthcare providers and their support staff with an understanding of AI women's unique needs which eventually lead to an increased participation in breast cancer screening. The provision of a comfortable and supportive environment during the screening can also positively influence women's perceptions and motivation in screening participation.

The main knowledge barrier identified by study participants was lack of information on the importance of early detection through screening and prevention of breast cancer. Previous studies have demonstrated that knowledge of breast cancer and screening guidelines are related to the increased screening rates ${ }^{[27,28]}$. Specific topics that emerged from this study were risk factors, and facts and myths about breast cancer and breast cancer screening. For those AI American women who were new immigrants (residing in the U.S. less than 10 years), information about available financial alternatives and assistance for participating in the screening may be particularly important. Therefore, it is crucial to have a variety of channels established to disseminate pertinent information regarding breast cancer screening and provide free or low-cost mammogram programs that are accessible geographically. Such information can be disseminated through local ethnic newspapers and Asian community-based organization websites and at the health fairs, temples, and community centers where these women gather. Public health programs that promote breast cancer screening can build upon existing knowledge among specific cultural groups and develop and implement culturally appropriate content that provides relevant information to AI women in formats that matches their needs. In addition, effective strategies for follow-up visits for those women who are currently in the health care system can further promote screening adherence. For example, the mammogram appointment for the following year can be made either when they are checking in or before they leave after the mammogram so that the women know when they are expected to get the next mammogram. In addition, developing a reminder system that uses a post card, email, and/or text-message to remind women about when their mammograms are due may increase the compliance for regular mammogram screening.

The current study has limitations. Our reliance on a small convenience sample to identify focus group participants that focused on women who had immigrated to the U.S. and currently resided in Michigan limits the generalizability of the findings to other groups of AI women. Yet, as generalizability is not a goal of qualitative research, this limitation is minimal. However, future qualitative research is needed to continue to expand our understanding of this population. For example, exploring perceptions of second-generation AI American women who were born in the United States or AI women who live in other geographic regions of the United States will be advisable. Another potential limitation may center around the fact that the focus group discussions were conducted on the culturally sensitive topic of breast cancer and breast exams. This may have hindered the participants' willingness to openly show their true feelings.

\section{Conclusion}

This study identified the facilitating factors and barriers related to breast cancer screening through focus groups for these 11 AI women. The study findings have implications for development of culturally-sensitive interventions to increase 
breast cancer screening among AI women as well as guide the prevention actions of healthcare providers serving the AI community. Education interventions that emphasize information about cancer risk and benefits of cancer screening and considers AI women's cultural beliefs can be useful to counter negative thoughts or misconceptions/myths about breast cancer and cancer screening. In addition, encouraging healthcare providers to reinforce motivating factors and address inhibiting factors during their clinical encounters can potentially improve breast cancer screening utilization among this population. It is important to address their specific needs to provide customized quality of care and to engage them in breast cancer screening.

\section{Acknowledgement}

This research was supported by Susan G. Komen for the Cure and the U.S. Department of Defense. We are extremely grateful to the AI American women who participated in the study as well as for the enormous effort of those who provided invaluable assistance in conducting this study: Aruna Choudhry, Joanna Brancroft, Nadia Charania, Scott Chung, Marjorie Frank and Alethea Helbig who provided editorial assistance with earlier drafts of the manuscript.

\section{Reference}

[1] Humes K, Jones N, Ramirez R. Overview of race and Hispanic origin: 2010 Census briefs. U.S. Census Bureau [Internet]. 2011. Available from: http://www.census.gov/prod/cen2010/briefs/c2010br-02.pdf

[2] Center for Disease Control and Prevention [Internet]. 2011. Asian American Population. Available from: http://www.cdc.gov/omhd/populations/AsianAm/AsianAm.htm.

[3] Miller CA, Chu KC, Hankey BF, Ries LAG. Cancer incidence and mortality patterns among specific Asian and Pacific Islander populations in the US. Cancer Causes Control. 2008; 19(3): 227-256. http://dx.doi.org/10.1007/s10552-007-9088-3

[4] Alagiakrishnan K, Chopra A. Health and health care of Asian Indian American elders. In Curriculum in ethnogeriatrics: Core curriculum and ethnic specific modules [Internet]. 2001. Available from:

http://www.stanford.edu/group/ethnoger/asianindian.html.

[5] Ghumare SS, Cunningham JE. Breast cancer trends in Indian residents and emigrants portend an emerging epidemic for India. Asian Pacific J Cancer Prevention. 2007; 8(4): 507-512. PMid:18260720

[6] Parikh-Patel A, Mills PK, Jain RV. Breast cancer survival among South Asian women in California. Cancer Causes Control. 2006; 17(3): 262-272. http://dx.doi.org/10.1007/s10552-005-0520-2

[7] Jain R, Mills P, Parikh-Patel A. Cancer incidence in the South Asian population of California, 1988-2000. J Carcinogenesis. 2005; 4: 21. PMid:16283945 http://dx.doi.org/10.1186/1477-3163-4-21

[8] Smith LK, Botha JL, Benghiat A, Steward WP. Latest trends in cancer incidence among UK South Asians in Leicester. Br J Cancer. 2003; 89(1): 70-73. PMid:12838302 http://dx.doi.org/10.1038/sj.bjc.6600973

[9] Levin B, Lieberman, DA, McFarland B, et al. Screening and Surveillance for the Early Detection of Colorectal Cancer and Adenomatous Polyps, 2008: A Joint Guideline From the American Cancer Society, the US Multi-Society Task Force on Colorectal Cancer, and the American College of Radiology. Gastroenterology. 2008; 134: 1570-1595. PMid:18384785 http://dx.doi.org/10.1053/j.gastro.2008.02.002

[10] Leitch M, Dodd GD, Costanza M, Linver M, Pressman P, McGinnis L, et al. American Cancer Society Guidelines for the early detection of breast cancer: update 1997. CA Cancer J Clin. 1997; 47: 150-153. http://dx.doi.org/10.3322/canjclin.47.3.150

[11] American college of obstetricians and gynecologists [Internet]. 2011. Annual Mammograms Now Recommended for Women Beginning at Age 40. Available from:

http://www.acog.org/About_ACOG/News_Room/News_Releases/2011/Annual_Mammograms_Now_Recommended_for_Wom en_Beginning_at_Age_40.

[12] Humphrey LL, Helfand M, Chan BK, Woolf SH. Breast cancer screening: a summary of the evidence for the U.S. Preventive services task force. Ann Intern Med. 2002; 137: 347-360. PMid:12204020

[13] Wingo PA, Ries LA, Giovino GA, et al. 1973-1996: With a Special Section on Lung Cancer and Tobacco Smoking. Annual report to the nation on the status of cancer, 1973-1996, with a special section on lung cancer and tobacco smoking. J Natl Cancer Inst. 1999; 91(8): 675-690. http://dx.doi.org/10.1093/jnci/91.8.675

[14] Centers for Disease Control and Prevention. Mammography: Mammography percentages by race and ethnicity [Internet]. 2009. Available from: http:www.cdc.gov/cancer/breast/statistics/screen.htm 
[15] Wu TY, Hsieh HF, West BT. Stages of mammography adoption in Asian American women. Health Edu Res. 2009; 24(5): 748-759. PMid:19318524 http://dx.doi.org/10.1093/her/cyp009

[16] Boxwala FI, Bridgemohan A, Griffith DM, Soliman AS. Factors associated with breast cancer screening in Asian Indian women in metro Detroit. J Immigr Minor Health. 2010; 12(4): 534-43. PMid:19629691 http://dx.doi.org/10.1007/s10903-009-9277-0

[17] United States Dept. of Health and Human Services. Healthy People 2010: Understanding and Improving Health. Washington: GPO, 2000.

[18] Ryerson AB, Miller J, Eheman CR, et al. Use of Mammograms among Women Aged 40 Years—United States, $2000-2005$. MMWR. 2007; 56(3): 49-51. PMid:17251897

[19] Parkington SR, Faine N, Nguyen MC, Lowery MT, Virginkar PA. Barriers to breast cancer screening in a managed care population. Manag Care. 2009; 34-45.

[20] Wu TY, Bancroft J. Filipino American women's perceptions and experiences with breast cancer screening. Oncol Nurs Forum. 2006; 33(4): E71. PMid:16858450 http://dx.doi.org/10.1188/06.ONF.E71-E78

[21] Bottoroff JL, Grewal S, Sullivan K. Punjabi women’s experiences of breast cancer. Social Res. 2006; 1-10.

[22] Im E, Park YS, Lee EO, Yun SN. Korean women's attitudes toward breast cancer screening tests. International J Nurs Studies. 2004; 41: 583-589. PMid:15240081 http://dx.doi.org/10.1016/j.ijnurstu.2004.01.004

[23] Krueger RA. Focus groups: A practical guide for applied research. Newbury Park, CA: Sage. 1988.

[24] Morgan DL. Focus groups as qualitative research. Newbury Park, CA: Sage. 1988.

[25] Owen S. The practical, methodological and ethical dilemmas of conducting focus groups with vulnerable clients. J Adv Nurs. 2001; 6: 652-658. PMid:11737497 http://dx.doi.org/10.1046/j.1365-2648.2001.02030.x

[26] Morgan DL, Krueger RA. When to use focus groups and why. In D.L. Morgan (Ed.), Successful focus groups: Advancing the state of the art Thousand Oaks, CA: Sage. 1994; 86-101.

[27] Valdez A, Banerjee K, Ackerson L, Fernandez M, Otero-Sabogal R, Somkin C. Correlates of breast cancer screening among low-income, low-education Latinas.Prev Med. 2001; 33: 495-502. PMid:11676592 http://dx.doi.org/10.1006/pmed.2001.0913

[28] Champion V, Miller A.Recent mammography in women aged 35 and older: Predisposing variables. Health Care Women In. 1996; 17: 233-245. PMid:8852225 http://dx.doi.org/10.1080/07399339609516238 